\title{
Is water out of vogue? A survey of the drinking habits of 2-7 year olds
}

\author{
L P M Petter, J O’B Hourihane, C J Rolles
}

\begin{abstract}
Objective-To survey the drinking habits of young children with reference to the consumption of plain water, and to estimate the proportion of a child's recommended energy intake contributed by drinks.

Design-A prospective survey.

Setting-Health centres, mother and toddler groups, and infant schools in and around Southampton.

Subjects-39 preschool and 66 infant schoolchildren.

Interventions-Parents kept a diary of all drinks consumed by the child over 48 hours. Parents were interviewed with a questionnaire about the drinking habits of their child.
\end{abstract}

Main outcome measures-The type of drinks and volume of fluid consumed over 48 hours; the proportion of a child's recommended energy intake consumed through drinks.

Results-72.5\% of the preschool group and $50 \%$ of the infant school group never drank plain water. Squash was by far the most frequently consumed drink. $15 \%$ of the preschool group consumed just under $50 \%$ of their recommended daily energy intake in drinks.

Conclusions-Young children consume large quantities of squash which constitutes a substantial energy supply. It is possible that they are conditioned at an early age to the sweet taste of drinks that may be of no nutritional benefit to them. (Arch Dis Child 1995; 72: 137-140)

Keywords: drinking habits, young children.

Observation in a paediatric outpatient clinic suggested that many young children attending were often found to be consuming large quantities of soft drinks, fruit juices, and other drinks. It was not known whether the consumption of large quantities of soft drinks was typically a part of an average child's diet.

Few nutritional surveys have been done on

Department of Child

Health, Level G,

Southampton

University Hospitals

Trust, Southampton

General Hospital,

Tremona Road,

Southampton SO9 4XY

L P M Petter

J O'B Hourihane

C J Rolles

Correspondence to:

Dr Rolles.

Accepted 19 October 1994

normal infants and toddlers, and several authors have commented on the scarcity of information available on normal fluid and water intake. ${ }^{1-3}$ In 1980, the Water Research Council found that infants consumed a significantly higher mean volume of squashes (see definitions in Subjects and methods) than children as a whole, and that squash consumption decreased with age. Tap water constituted about half of the total fluid intake of the 1-4 and 5-11 year old age groups. As with many other studies it did not distinguish between plain water (see definitions) consumed on its own and tap water used to make up other drinks. ${ }^{4}$ Murray found that $42 \%$ of all squashes are consumed by $2-9$ year olds. ${ }^{5}$ Some early studies found that plain water made up $15.8-25.5 \%$ of total fluid intake in children from 1-14 years. ${ }^{367}$ Galagan et al give corresponding values from $33 \cdot 8-36 \cdot 4 \%$ for 1-10 year olds. ${ }^{8}$ In each case, a very small percentage of the total fluid intake was made up of soft drinks. Neumann found that $29 \%$ of 6 month to 5 year olds never drank plain water. ${ }^{2}$

A review of the commercial data shows that soft drink consumption has increased in the last 10 years. ${ }^{9} \mathrm{~A}$ large proportion of soft drinks are consumed by children. ${ }^{10}$ Sixty per cent of all squash is consumed by the under 15 age group and carbonates are now also growing in popularity with the young. ${ }^{11}$

Our study was, therefore, an attempt to survey the drinking habits of young children with particular reference to the consumption of plain water. Replacing plain water with soft

\section{Preschool}

Never $(71.8 \%)$

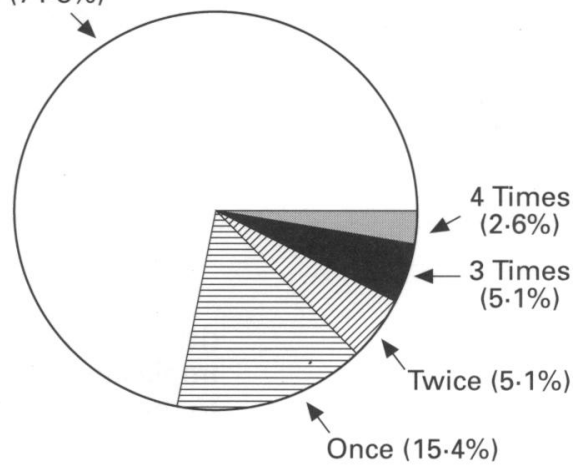

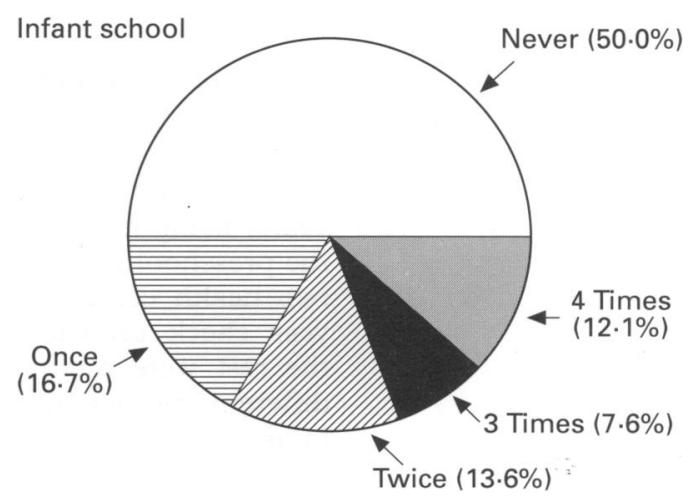

Figure 1 Frequency of plain water consumption over 48 hours in the preschool and the infant school groups. 

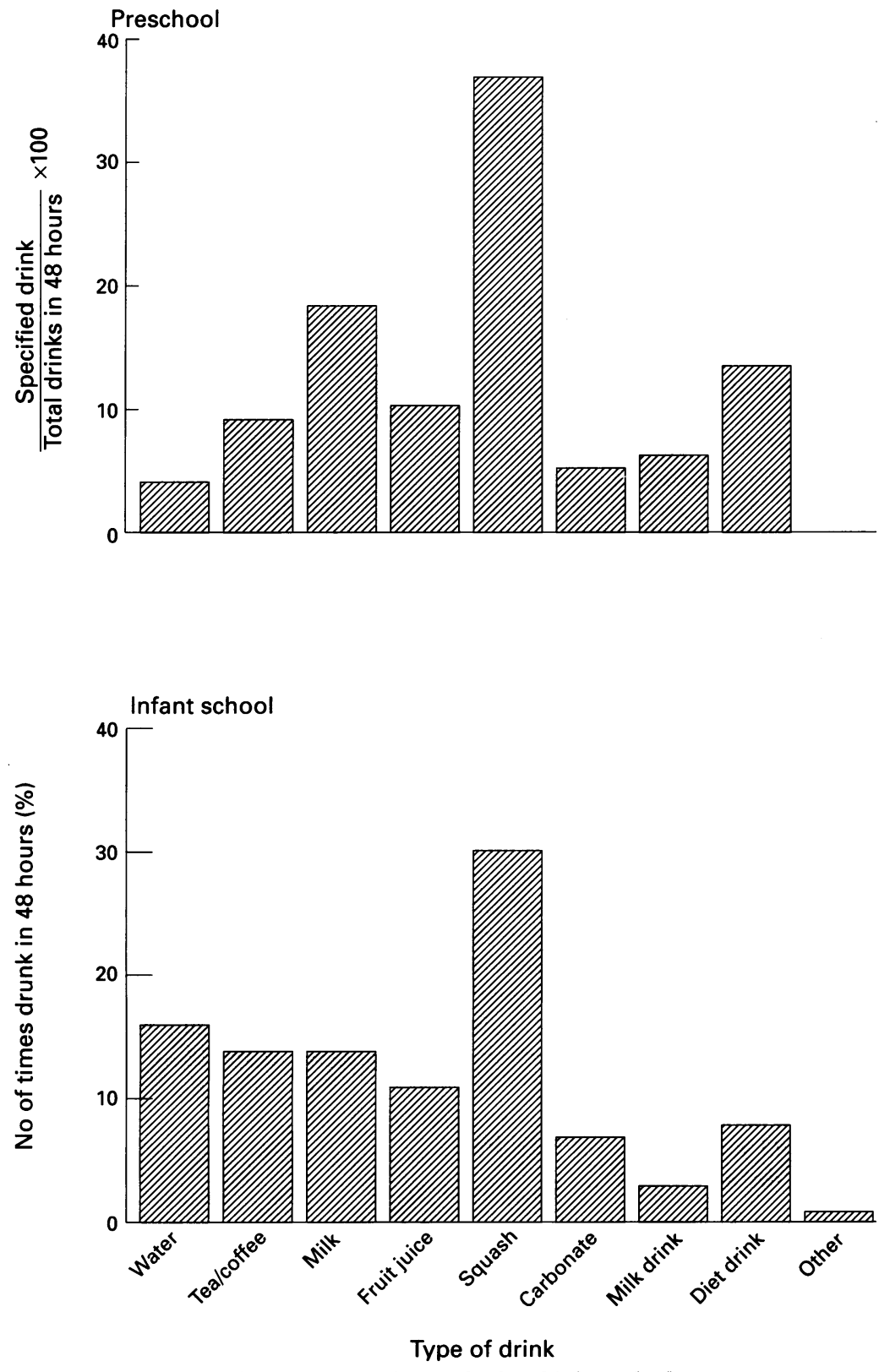

Figure 2 Popularity of drink types in the preschool and infant school groups.

drinks may have several significant nutritional implications such as poor weight gain, failure to thrive, and bowel disturbances. ${ }^{12}$ This study also aimed to estimate the proportion of a child's recommended daily energy allowance that is contributed by drinks.

\section{Subjects and methods}

The study population consisted of 39 healthy preschool (aged $2 \cdot 1$ to 4.3 years) and 66 healthy infant schoolchildren (aged $5 \cdot 5$ to $7 \cdot 0$ years) living in and around Southampton. Of the preschool group, nine were recruited from two health centres while attending their two year check up with the health visitor, and the rest were recruited while attending four different mother and toddler groups. In the infant school group, parents of each child in the middle two classes of three different local infant schools were contacted by letter. If cooperative, they were met in person while collecting their children from school and gave verbal consent to taking part.

Information was gained from a drink diary kept by the parent and a semistructured questionnaire. The diary recorded all drinks consumed by the child on one weekday and one weekend day, including the time it was consumed, the full brand name, and the volume consumed using household measures. In the infant school group the provision of drinks was supervised by the teachers. Those taking flasks of drink to school brought home anything they left over and this was measured by the parent. After completion of the two day study period, the parents were visited in their homes to collect the diaries and interviewed with the questionnaire. All household measures were calibrated with a measuring cylinder and the volume of each drink and each constituent of the drink (for example, squash) was recorded.

The centile for weight of each subject was plotted using standard child growth charts. ${ }^{13}$ The energy content of each drink consumed was calculated using nutritional information given on the label of the drink or from information from the manufacturers. When this was not available, standard food composition tables were used or the value for another brand of the same drink was taken. ${ }^{14}$

The definitions used were:

(1) Drink: any non-alcoholic beverage. Includes milk, soft drinks, tea, coffee, milk based drinks, plain water.

(2) Soft drink: collective term for squashes, carbonates, fruit juices, fruit drinks.

(3) Plain water: ordinary tap water consumed on its own as a drink.

(4) Squash: concentrated fruit and other flavoured drink to which water is added before consumption. Includes squashes which are sold already diluted.

(5) Fruit juice: $100 \%$ pure fruit juice at the same strength and consistency as when the fruit was originally squeezed.

(6) Carbonate: any effervescent soft drink, aerated with carbon dioxide.

(7) Milk drink: any drink, hot or cold, in which milk is the basic constituent and to which a flavoured powder or syrup is added.

(8) Diet drink: any soft drink with a reduced sugar content.

Results were analysed using the SPSS-X statistical package (SPSS Inc, SPSS-X user's guide, 1988). Approval by the regional district committee was given for the study to take place.

\section{Results}

The parents of 114 children completed the diaries and questionnaires. Of these, nine were excluded for recording incomplete information, leaving a total of 105, 39 from the preschool group (17 boys) and 66 from the infant school group ( 35 boys). The heights and weights of the children were distributed normally.

Figure 1 illustrates the frequency of plain water consumption over 48 hours in each age 

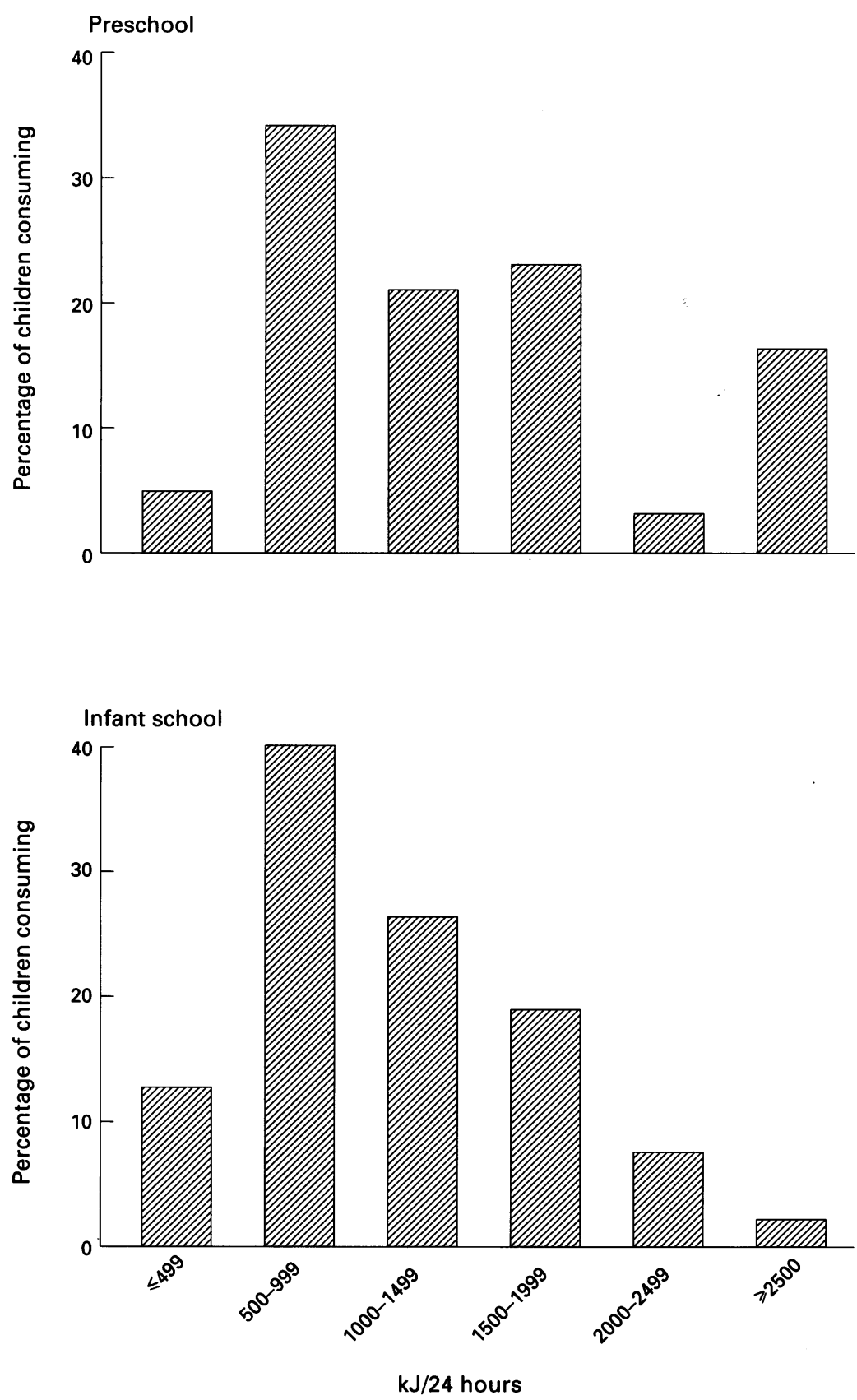

Figure 3 Energy intake through drinks over 24 hours in the preschool and infant school groups. mothers were happy about their child's drinking habits.

The mean (SE) fluid intake over 24 hours for the preschool group was 1018 (120) ml (that is half the value for 48 hours) and for the infant school group, 941 (94) $\mathrm{ml}$.

Figure 3 illustrates the energy intake through drinks of both age groups. The mean energy intake through drinks over 24 hours was $1431 \mathrm{~kJ}$ for the preschool group and 1121 $\mathrm{kJ}$ for the infant school group. Taking the recommended energy intake over 24 hours for 2-3 year olds as $5670 \mathrm{~kJ}(15), 15 \%$ of the preschool group consumed almost 50\% $(2500 \mathrm{~kJ}+)$ of their recommended energy intake in drinks.

No significant difference in energy intake, fluid intake, or mean centile for weight was found between those subjects who drank plain water during the recording period and those who did not.

\section{Discussion}

Our results show that most of this population did not drink plain water routinely. Squash was by far the most frequently consumed drink in both age groups. On questioning the mothers, they seemed happy with their child's drinking habits. Plain water has largely been replaced by squash, especially among the preschool group. The reason given was simply that the children did not like the taste of plain water. This may imply that, as suspected, children have been conditioned as early as the age of 2 to the sweet taste of squash, to the extent that they refuse to drink a more tasteless alternative.

The actual total energy intake of the subjects was not recorded in this survey. Evidence shows, however, that this is fairly similar to the recommended intake at this age. ${ }^{15-17}$ It is recommended that at least half of a child's energy intake should be from carbohydrate and that most of this should be in the form of starch, as this is usually associated with useful nutrients. ${ }^{18}$ In the preschool group $15 \%$ were getting almost the equivalent of their recommended carbohydrate intake through drinks such as squash, which is associated with few useful nutrients. Due to diminished appetite, this could lead to a child missing out on valuable nutrients at mealtimes, or conversely encourage excessive energy intake and obesity.

Another concern is the effect of drinking large quantities of sugary drinks on the dentition of children. There is a direct link between the development of dental caries and the frequency of sugar taken by mouth. ${ }^{5} 19$

Potential drawbacks of the study are the small size of the population and the fact that all the results were subject to the bias of maternal reporting. Schools, health centres, and mother and toddler groups were deliberately selected from different socioeconomic areas on the basis of advice from health care professionals working in the area. As only two out of 11 $(18.2 \%)$ children did not attend their two year check up at the health centre, it is unlikely that this population was selected completely by maternal motivation. 
Market sector reports claim there is 'huge potential' for growth in the soft drinks market in the UK and provide recommendations on how to target promotional emphasis. ${ }^{2021}$ Parents with young children are a vulnerable population who are anxious for the wellbeing of their children and may have limited financial resources. In some retail stores many of the barley waters and blackcurrant squashes are promoted as 'health drinks' and are sometimes displayed in separate areas of the shop from other soft drinks. The large drinks manufacturers are benefiting from the drinking habits of young children. ${ }^{21}$

This survey shows that young children drink large quantities of squash and similar drinks that may constitute a substantial energy supply and may diminish their appetite. Children are targeted consumers being unwittingly conditioned not to drink plain water. This may well have a significant impact on their nutritional and dental health. Further research is recommended to explore this impact in greater depth.

This paper is based on a study done by the first author in the 4th year at the University of Southampton Medical School.

1 Margolis FJ, Walker JS, Luten-Teate H, Weil ML, Wilson HL. Water intake of normal children. Science 1963; 140: 890-1.

2 Neumann HH. The milk and water intake of small children. Archives of Pediatrics New York 1957; 74: 456-62.

3 Crosby ND, Shepherd PA. Studies on patterns of fluid intake, water balance and fluoride protection. Med $\mathcal{F}$ Aust 1957; ii: 305-11.

4 Hopkin SM, Ellis JC. Drinking water consumption in Great Britain. A survey of drinking habits with special reference to tap-water-based beverages. (Technical report 137.)
Marlow: Water Research Centre, 1980 .

5 Smith AJ, Shaw L. Baby fruit juices and tooth erosion. $\mathrm{Br}$ Dent f 1987; 162: 65-7.

6 McPhail CWB, Zacherl W. Fluid intake and climatic temperature: relation to fluoridation. $f$ Can Dent Assoc 1965; 31: 7-16.

7 Longwell J. Symposium on the fluoridation of public water supplies (d): chemical and technical aspects. Royal Society of Health fournal 1957; 73: 361-70.

8 Galagan DJ, Vermillion JR, Nevitt GA, Stadt ZM, Dart RE. Climate and fluid intake. Public Health Rep 1957; 72: 484-90.

9 British Soft Drinks Association. Soft drinks today (Soft drinks sales Factsheet No 9.) London: British Soft Drinks Arinks sales Factshe

10 Cooperative Wholesale Society. National drinks survey. Manchester: Cooperative Wholesale Society, Food Manufacturing Group, 1988 (No 12).

11 Anonymous. Carbonates and squashes. Market sector report. Bristol: Mintel Market Intelligence, Feb 1988

12 Greene HL, Ghisham FK. Excessive fluid intake as a cause of chronic diarrhoea in young children. $\mathcal{f}$ Pediatr 1983; 102: $836-40$.

13 Gairdner-Pearson. Height and weight standard charts. Welwyn Garden City: Castlemead Publications, 1988.

14 Holland B, Welch A, Unwin ID, Buss DH, Paul A, Southgate DAT. McCance and Widdowson's the composition of foods. 5th Ed. Cambridge: Royal Society of Chemistry and the Ministry of Agriculture, Fisheries and Food, 1991.

15 DHSS. A nutrition survey of pre-school children 1967-68. (Report on health and social subjects No 10.) London: HMSO, 1975 .

16 Whitehead RG, Paul AA, Cole TJ. Analysis of measured food energy intakes during infancy and early childhood in food energy intakes during infancy and early childhood in comparison with current international recommal of Human Nutrition 1981; 35: 339-48.

17 Whitehead RG, Cole TJ. Trends in food energy intakes throughout childhood from 1-18 years. Human Nutrition: Applied Nutrition 1982; 36: 57-62.

18 DHSS. Committee on Medical Aspects of Food Policy. Recommended daily amounts of food energy and nutrients for groups of people in the UK. (Report on health and social subjects No 15.) London: HMSO, 1979.

19 Murray JJ, ed. The prevention of dental disease. Oxford: Oxford Medical Publications, 1983.

20 Anonymous. Soft drinks. Market sector report. Bristol: Gateway Food Markets, Marketing Department, Feb 1988.

21 Anonymous. Concentrated soft drinks. Bristol: Mintel Market Intelligence, Dec 1992. 